\title{
Screening And Genome Sequencing of a di-n-butyl Phthalate Degrading Bacterium J2 Isolated From Peanut Field Soil
}

\section{Mingqing Wang ( $\triangle$ mingqing201610@163.com )}

Shandong Peanut Research Institute https://orcid.org/0000-0002-0878-444X

Lina Yu

Shandong Peanut Research Institute

Jie Sun

Shandong Peanut Research Institute

Jie Bi

Shandong Peanut Research Institute

Yu Song

Shandong Peanut Research Institute

Weiqiang Yang

Shandong Peanut Research Institute

Cheng Jiang

Shandong Peanut Research Institute

Chengren Shi

Shandong Peanut Research Institute

Kuijie Gong

Shandong Academy of Agricultural Sciences

Mei Wang

Shandong Academy of Agricultural Sciences

Qiang Yao

Shandong Academy of Agricultural Sciences

Yanjie Dong

Shandong Academy of Agricultural Sciences

\section{Research Article}

Keywords: Di-n-butyl phthalate, Biodegradation, Priestia, Soil, Genome, Gene

Posted Date: December 28th, 2021

DOl: https://doi.org/10.21203/rs.3.rs-1120370/v1 
License: (c) (i) This work is licensed under a Creative Commons Attribution 4.0 International License. Read Full License 


\section{Abstract}

Di- $n$-butyl phthalate (DBP) is commonly used plasticizers in agricultural plastic films, and is a priority pollutant due to its toxicity to human health. A newly isolated strain $\mathrm{J} 2$, which used DBP as its sole carbon source, was screened from peanut filed soil by continuous enrichment cultivation. Based on morphological, physiological characteristics and 16S rRNA gene sequence analysis (GenBank accession No. OK598965), it was identified as Priestia sp. J2. The research results revealed the optimal conditions for DBP degradation as $35^{\circ} \mathrm{C}$ and $\mathrm{pH}$ 8.0. The strain could effectively degrade $97.6 \%$ DBP within 5 days. Substrate tests showed that strain J2 could utilize shorter side-chained PAEs, but could not utilize longchained PAEs. The whole genome comprises a complete chromosome of 5,067,299 bp and four plasmids of 147,924 bp, 75,940 bp, 11,604 bp, 11,333 bp (GenBank accession No. CP086208-CP086212). This genome harbors 5,585 predicted protein-encoding genes, 130 tRNA genes, and 42 rRNA genes. Gene annotation analyses showed a DBP-degrading gene contained an open reading frame of $930 \mathrm{bp}$, and the enzyme was named Est-J2-1. The amino acid sequence of the Est-J2-1 exhibited no significant homology with those of reported DBP-degrading enzymes, suggesting the enzyme is a novel enzyme. The gene of Est-J2-1 was found to be located on the chromosome. This study provided strain resource for DBP removal from farmland and other environments.

\section{Introduction}

Plastic films can maintain soil moisture, regulate soil temperature and restrict weed growth to promote crop yield, which play an indispensable role in modern agricultural production (Sun et al. 2020). Phthalate acid esters (PAEs) are widely added as plasticizers in the production process of plastic films (Zhang et al. 2021). PAEs are easy to accumulate and migrate in soil and water environment (Vikelsoe et al. 2002; Le et al. 2021). As environmental hormones, they can affect human reproduction and induce genetic aberrations (Surhio et al. 2017). Some PAEs, such as di-n-butyl phthalate (DBP), diethyl phthalate (DEP), Dioctyl Phthalate (DOP), have been classified as priority pollutants in USA, European Union and China. DBP has been widely used in agricultural plastic films, mainly as plasticizer. Because DBP is only physically bound to plastic structures, it tends to escape into soil, water and other environments. Therefore, DBP is be detected in various soil, groundwater, and other environmental samples. In addition, DBP can be absorbed by crops into the food supply, threatening human and animal health (Wang et al. 2016).

DBP removal methods include hydrolysis, photo degradation, and biodegradation. However, because of the inefficiency of the first two methods, biodegradation plays a major role in the DBP degradation. Biodegradation is considered a promising and environmentally friendly method to eliminate DBP. Many microorganisms capable of degrading DBP were be screened, including Rhodococcus ruber (Li et al. 2006), Pseudomonas aeruginosa (Tang et al. 2021), Bacillus subtilis (Xu et al. 2020), Arthrobacter sp. (Liu et al. 2020), Pleurotus ostreatus (Ahuactzin-Pérez et al. 2018). Only a few identified enzymes involved DBP degradation have been reported. A phthalate esters hydrolase DphB was identified through a metagenomic library isolated from wastewater, which could degrade DBP (Ding et al. 2015). A DBP- 
degradation enzyme was found from Sulfobacillus acidophilus DSM10332, named EstS1t (Zhang et al. 2014). DBP hydrolase was found in Acinetobactersp. M673 (Wu et al. 2013).

In this study, a DBP-degrading strain J2 from peanut field soil was screened and identified. Strain J2 could utilize DBP to grow, with high degradation activity. We investigated the DBP degradation characteristics of strain $\mathrm{J} 2$, and further sequence the genome to study the DBP-degrading genes.

\section{Materials And Methods}

\section{Reagents, samples and cultivation medium}

DBP, DEP, DOP, dimethyl phthalate (DMP), diisooctyl phthalate (DIOP) and diisononyl phthalate (DINP) were purchased from Sigma-Aldrich (USA). The methanol was HPLC grade from Merck. The rest of chemical reagents were analytical grade, obtained from China National Medical Medicine Group. The soil samples of peanut field were collected from Laixi Experimental Station of Shandong Peanut Research Institute in Qingdao, Shandong Province, China. All samples were stored at $4{ }^{\circ} \mathrm{C}$ before analysis. The mineral salt medium (MSM) was prepared as previously described (Wu et al. 2011). DBP was added, and the solution was sterilized at $120^{\circ} \mathrm{C}$ for $15 \mathrm{~min}$.

\section{Enrichment, screening and identification of DBP-degrading bacteria}

DBP-degrading bacteria were screened from peanut field soil by continuous enrichment cultivation. 1 gram soil sample was inoculated to $200 \mathrm{ml}$ of solution with $200 \mathrm{mg} / \mathrm{L}$ DBP. After 7 days, $1000 \mu \mathrm{l}$ of the culture added to $200 \mathrm{ml}$ solution with $1000 \mathrm{mg} / \mathrm{L}$ DBP. After 7 days, $100 \mu \mathrm{L}$ samples were spread onto MSM agar with DBP under sterile conditions, and then the plates were incubated at $28^{\circ} \mathrm{C}$ for $5-10$ days until colonies appeared. Single colony was isolated and subsequently transferred to MSM agar for three times, and the pure culture was named $\mathrm{J} 2$.

The morphology of strain J2 was observed on LB agar plates after $16 \mathrm{~h}$ at $28^{\circ} \mathrm{C}$. The hydrolysis of casein, starch, gelatin, Tween 40, Tween 80 and gelatin was studied as described in previous reports (Romanenko et al. 2013). The strain J2 was identified by $16 \mathrm{~S}$ rRNA gene sequencing. 27F and 1492R primers were used for PCR amplification (Frank et al. 2008). PCR amplification products were analyzed using $0.8 \%$ agarose gel, and were then purified. The fragments were linked into pMD19-T, and then were transformed into competent cells. The DNA sequencing was performed using an DNA sequence analyzer ABI 3720 (Applied Biosystems, United States) by Shanghai Personalbio. The 16S rRNA gene sequence was analyzed in Ezbiocloud database. The phylogenetic tree was then constructed using MEGA X (Kumar et al. 2018).

\section{Substrate utilization experiments}

In order to study strain $\mathrm{J} 2$ to degrade PAEs, the bacterium was inoculated into MSM containing $0.3 \mathrm{~g} / \mathrm{L}$ of one of PAEs: DBP, DMP, DEP, DOP, DIOP, DINP. Uninoculated media supplemented with each substrate were 
used negative controls. The suspension was cultured on a rotating shaker at $28^{\circ} \mathrm{C} .5$ days later, substrate utilization was measured using optical density method.

\section{Biodegradation of DBP by strain $\mathrm{J} 2$}

Strain J2 was first cultured in LB medium at $28{ }^{\circ} \mathrm{C}$ for $24 \mathrm{~h}$. Strain J2 was harvested and washed three times with phosphate buffer, and then was suspended in the phosphate buffer. Inoculated $1 \%$ bacterial solution into $50 \mathrm{~mL}$ MSM with $1000 \mathrm{mg} / \mathrm{L} \mathrm{DBP}$. In order to study the optical conditions of degradation, the degradation of $1000 \mathrm{mg} / \mathrm{L}$ DBP by strain $\mathrm{J} 2$ was investigated under $\mathrm{pH}$ 5.0, 6.0, 7.0, 8.0, 9.0 and 10.0, and different temperature $\left(18,28,35,40,45^{\circ} \mathrm{C}\right)$. After 5 days, the residue remaining DBP was investigated using HPLC.

\section{Analysis of DBP biodegradation using HPLC}

The samples were mixed with ethyl acetate at a 1:1 vol ratio. The aqueous phase was separated using centrifugation at $8,000 \mathrm{~g}$. The aqueous solution samples were extracted twice. The ethyl acetate was evaporated by a rotary evaporator (Buchi, Switzerland). The residue was dissolved in $10 \mathrm{ml}$ methanol, and then filtered. Finally, HPLC was used to analyze the residual concentration of DBP with C18 column. The experiment was carried out at a column temperature of $30^{\circ} \mathrm{C}$, with a mixture of methanol and water at a ratio of 90:10 (v/v). The concentrations of residual DBP were quantified by comparing the integral values of the peak area with the calibration standard curve. DBP degradation efficiency was evaluated, based on the initial and final concentrations of DBP in the test solution.

\section{Genome sequencing}

The whole genome of strain J2 was sequenced by using PacBio RS II Single Molecule Real Time (SMRT) and Illumina sequencing platform, provided by Shanghai Majorbio Biopharmaceutical Technology Co., LTD. For PacBio sequencing, $20 \mu \mathrm{g}$ DNA of strain J2 was spun in a Covaris G-tube. The DNA fragments were then purified, repaired at the end, and linked with SMRTbell sequencing adapters. The sequence library was constructed by $0.45 \mathrm{x}$ volumes of Agencourt AMPure XP beads. An insertion library of about $10 \mathrm{~kb}$ was sequenced on one SMRT cell. For Illumina sequencing, more than $1 \mu \mathrm{g}$ DNA samples were used for sequencing. According to the manufacturer's protocol, genomic DNA samples were cut into 400500 bp fragments. The libraries were sequenced on Illumina HiSeq X Ten machine with $2 \times 150 \mathrm{bp}$.

\section{Annotation of Genomic Information}

CDS, transfer RNA (tRNA) genes and ribosomal RNA (rRNA) genes were predicted by Glimmer (Delcher et al. 2007), Trnascan-SE (Lowe et al. 1997) and rRNAmmer (Lagesen et al. 2007), respectively. The CDSs were annotated based on six databases, including NR, Swiss-Prot, Pfam, GO, COG and KEGG, using several sequence alignment tools (Besemer et al. 2001; Kanehisa et al. 2004; Tatusov et al. 2003). DNAMAN software was used for multiple sequence alignment of esterase. 


\section{Results And Discussion}

\section{Identification of DBP-degrading bacteria}

The bacteria were screened from peanut field soil collected from Laixi Experimental Station of Shandong Peanut Research Institute. After continuous enrichment culture, strain J2 could utilize DBP to grow, with high degradation activity. Therefore, the strain J2 was selected for further study. The colonies of strain J2 appeared on LB agar plates were circular, creamy white, raised (Fig. 1). It is a gram-positive bacterium. The physiological and biochemical of strain $\mathrm{J} 2$ are shown in Table 1. It was able to hydrolyze gelatin, casein, starch, urea, but not to hydrolyze Tween 80 . It could use glucose, arabinose, mannose, maltose, mannitol and N-Acetyl-glucosamine, but could not assimilate citric acid, proline, malic acid or phenylacetic acid. The $16 \mathrm{~S}$ rRNA gene of strain J2 was $1513 \mathrm{nt}$ (Fig. 2), and has been submitted to GenBank with the accession number OK598965. Through 16S rRNA gene sequencing and a BLAST homology search, strain J2 shared $16 \mathrm{~S}$ rRNA gene similarity of $99.93 \%, 99.80 \%, 98.78 \%, 98.17 \%, 97.76 \%$, 96.07\% with $P$. aryabhattai B8W22 ${ }^{\top}$, P. megaterium NBRC $15308^{\top}$, P. flexus NBRC $15715^{\top}$, P. qingshengii $\mathrm{G}_{19}{ }^{\top}$, P. paraflexus $\mathrm{RC} 2^{\top}$, P. koreensis DSM $16467^{\top}$. Phylogenetic analysis clearly indicated that strain J2 was a member of the genus Priestia (Fig. 3). In conclusion, the morphological, physiological and genetic sequence analyses identified strain $\mathrm{J} 2$ as belonging to the genus Priestia. Therefore, the strain was named Priestia sp. J2.

Table 1

Biochemical and physiological characteristics of strain J2

\begin{tabular}{|llll|}
\hline Item & Result & Item & Result \\
\hline Gelatin & + & Mannose & + \\
Casein & + & Citric acid & - \\
Starch & + & L-proline & - \\
Tween 40 & - & Malic acid & - \\
Tween 80 & - & Phenylacetic acid & - \\
Arginine & - & Maltose & + \\
Glucose & + & N-Acetyl-glucosamine & + \\
Arabinose & + & Mannitol & + \\
\hline
\end{tabular}

\section{Substrate utilization tests}

The substrate utilization test results indicated that the strain has differing abilities for degrading PAEs. The strain could grow well in media containing DBP, DMP and DEP, but could not grow well in DOP, DIOP or DINP (Table 2). DBP, DMP and DEP were shorter alkyl-chained PAEs, but DOP, DIOP and DINP were 
longer alkyl-chained PAEs. These results indicated that the side chain of substrates has a significant effect on the ability of strain $\mathrm{J} 2$ to degrade PAEs, which is consistent with the previous studies. Sphingobium sp. TJ could use DMP, DBP, DEP and MBP, but could use DOP and DIOP (Jin et al. 2013). Pseudomonas sp. YJB6 could use in the media of DBP, DMP and DEP, but could not grow better in the media of DEHP (Feng et al. 2021). Microbacterium sp. USTB-Y could assimilate DMP and DEP, but could not use DOP, DEHP and PA (Zhao et al. 2021).

Table 2

Substrate utilization test results of strain $\mathrm{J} 2$

\begin{tabular}{|lllllll|}
\hline Substrate & DBP & DMP & DEP & DOP & DIOP & DINP \\
\hline utilization + & + & + & - & - & - \\
\hline \\
+ positive -negative
\end{tabular}

\section{Characteristics of DBP degradation}

The effect of $\mathrm{pH}$ on DBP degradation by strain $\mathrm{J} 2$ was investigated at $35^{\circ} \mathrm{C}$. The degradation rate of DBP increased with the increase of $\mathrm{pH}$ from 5.0 to 8.0. Strain $\mathrm{J} 2$ had the highest degradation rate of DBP at $\mathrm{pH}$ 8.0. As pH exceeded 8.0, the degradation rate decreased sharply (Fig. 4A). In temperature experiment, when the temperature raised from $18{ }^{\circ} \mathrm{C}$ to $35^{\circ} \mathrm{C}$, the degradation rate of DBP increased rapidly (Fig. 4B). However, when the temperature reached $40^{\circ} \mathrm{C}$, the degradation rate decreases obviously. Strain $\mathrm{J} 2$ could not grow at $45^{\circ} \mathrm{C}$. Therefore, the optimal conditions for DBP degradation were $35^{\circ} \mathrm{C}$ and at pH 8.0. Jin et al. reported that the efficiency of DBP degradation was the highest, when $\mathrm{pH}$ value reached 7.0 (Jin et al. 2015). Achromobacter denitrificans Sp1 could degrade DEHP efficiently at pH 8.0 and $35^{\circ} \mathrm{C}$. Xu et al. reported that Pseudomonas fluorescens B-1 could degrade DBP efficiently at pH 7.0 (Xu et al. 2015). Strain $\mathrm{J} 2$ and the reported bacteria had the same trend in the optimization of degradation conditions.

Under optimal conditions, strain J2 could degrade $97.6 \%$ of $1000 \mathrm{mg} / \mathrm{L}$ DBP within 5 days. Some bacteria played important roles in DBP degradation. For example, Pseudomonas sp. W1 could degrade effectively degrade DBP (Wang et al. 2020). Rhodococcus ruber CQ0301 was able to degrade DBP (Li et al. 2006). Achromobacter sp. W-1 identified from wastewater could utilize DBP (Jin et al. 2015). Sphingobium sp. TJ isolated from the Haihe estuary cloud grow on mixed PAEs (Jin et al. 2013). Gordonia sp. QH-11 identified from sludge was reported to use DBP (Jin et al. 2012). Enterobacter sp. DNB-S2 could degrade $91.08 \%$ DBP at $50{ }^{\circ} \mathrm{C}$ within 7 days (Sun et al. 2019). Arthrobacter nicotianae ZM05 isolated from soil was efficient at degrading DBP (Wang et al. 2021). Based on the analysis of previous reports, many genera could degrade DBP. This study was the first report that Priestia genus could degrade DBP.

\section{Genome analysis and DBP-degrading genes analysis}


The complete genome of strain J2 contains one complete circular chromosome of 5,067,299 bp, and four circular plasmids (147,924 bp, 75,940 bp, 11,604 bp, 11,333 bp, respectively) (Fig. 5). The genome sequences in this study have been submitted to GenBank under the accession number CP086208CP086212. As shown in Table 3, GC content is $38.06 \%$ and the number of predicted coding sequences is 5,585 , accounting for $83.55 \%$ of the whole genome. The chromosome of strain J2 contains 112 tRNA genes and 39 rRNA operons. The plasmid A has 1 tRNA genes and 0 rRNA operons. The plasmid $B$ has 17 tRNA genes and 3 rRNA operons. The plasmid $C$ and $D$ have no tRNA and rRNA genes. Among the coding genes, 4210 (79.34\%), 2553 (48.12\%) and 3085 (58.14\%) genes are categorized against the COG, KEGG and $\mathrm{GO}$ databases, respectively.

Table 3

General features of Priestia sp. J2

\begin{tabular}{|llllll|}
\hline & $\mathbf{1}$ & $\mathbf{2}$ & $\mathbf{3}$ & $\mathbf{4}$ & $\mathbf{5}$ \\
\hline Length (bp) & 5067299 & 147924 & 75940 & 11604 & 11333 \\
\hline GC content (\%) & $38.25 \%$ & $33.15 \%$ & $36.31 \%$ & $34.16 \%$ & $32.86 \%$ \\
\hline Total CDSs & 5306 & 186 & 69 & 14 & 12 \\
\hline tRNA genes & 112 & 1 & 17 & 0 & 0 \\
\hline rRNA genes (5S,16S, 23S) & $39(13,13,13)$ & $0(0,0,0)$ & $3(1,1,1)$ & $0(0,0,0)$ & $0(0,0,0)$ \\
\hline Genes assigned to COG & 3977 & 113 & 37 & 4 & 6 \\
\hline Genes assigned to KEEG & 2491 & 51 & 9 & 0 & 2 \\
\hline Genes assigned to GO & 2986 & 70 & 21 & 6 & 2 \\
\hline 1, 2, 3, 4, 5 were Chromosome, Plasmid A, Plasmid B, Plasmid C, Plasmid D, respectively. \\
\hline
\end{tabular}

In general, biodegradation of PAEs is caused by esterases, which catalyze hydrolysis of ester bonds (Jin et al. 2013). However, esterase research is still lacking. In this study, based on six databases, there were a large number of genes encoding for putative esterase/carboxylesterase and hydrolase/ $\alpha / \beta$ hydrolase. According to sequence alignment, almost all these esterases showed no significant homology to those of three reported DBP-degrading enzymes, EstS1 (AEW03609), DphB (KC438416) and DBP hydrolase (AFK31309) (Ding et al. 2015; Zhang et al. 2014; Wu et al. 2013), implying that there may be new DBPdegrading genes. A gene from Priestia sp. J2 annotated as "carboxylesterase" was named Est-J2-1, whose amino acid sequence showed $36.66 \%, 31.08 \%$ and $25.34 \%$ identity with above three DBPdegrading esterase.

The sequence comparison revealed that the sequence of Est-J2-1 shared no intensive homology with the three enzymes. Thus, the results indicated that Est-J2-1 was a novel member of the DBP hydrolase family. The gene of Est-J2-1 was found to be located on the chromosome. Sequence analysis of Est-J2-1 gene indicated that the open reading frame consisted of $930 \mathrm{bp}$ encoding 310 amino acids. The molecular weight of Est-J2-1 was 34700.14 Da and the isoelectric point was 5.04. No signal peptide 
sequence was found. Est-J2-1 and the three DBP-degrading enzymes had highly conserved functional motifs. The catalytic triad (Ser-Asp-His) and consensus motif (Gly-X-Ser-X-Gly) around the active-site Ser154 are boxed in the black frame (Fig. 6).

\section{Conclusion}

In conclusion, the strain $\mathrm{J} 2$ isolated from peanut field soil could use DBP as its sole carbon source. Based on morphological, physiological characteristics and 16S rRNA gene sequence analysis, it was identified as Priestia sp. J2. This study was the first report that Priestia genus could degrade DBP.

The research results indicated that the optimal conditions for DBP degradation were $35^{\circ} \mathrm{C}$ and at pH 8.0. Strain J2 could effectively degrade $97.6 \%$ DBP within 5 days. The genome of strain J2 contains one complete circular chromosome (5,067,299 bp) and four plasmids (147,924 bp, 75,940 bp, 11,604 bp, 11,333 bp, respectively). A novel DBP-degrading enzyme was identified, and contained 310 amino acids. This study provided strain resource for DBP removal from farmland and other environments.

\section{Declarations}

\section{Acknowledgments}

This work was supported by the grants from Major Application Technology Innovation of Agriculture in Shandong Province (SD2019ZZ012), Major Agricultural Application Technology Innovation of Shandong Province in 2018, Qingdao Science and Technology Benefit the People Demonstration and Guidance Special Project (20-3-4-33-nsh), Innovation Project of Agricultural Science and Technology of Shandong Academy of Agricultural Sciences (CXGC2021A19, CXGC2021A33), Natural Science Foundation of Shandong Province (ZR202103010513)

Conflict of interest The authors declare no conflict of interests.

\section{References}

1. Ahuactzin-Pérez M, Tlécuitl-Beristain S, García-Dávila J, Santacruz-Juárez E, González-Pérez M, Gutiérrez-Ruíz MC, Sánchez C (2018) Kinetics and pathway of biodegradation of dibutyl phthalate by Pleurotus ostreatus. Fungal Biol 122(10):991-997

2. Besemer J, Lomsadze A, Borodovsky M (2001) GeneMarkS: a self-training method for prediction of genes starts in microbial genomes. Implications for finding sequence motifs in regulatory regions. Nucleic Acids Res 29(12):2607-2618

3. Delcher AL, Bratke KA, Powers EC, Salzberg S, Notes A (2007) Identifying bacterial genes and endosymbiont DNA with GLIMMER. Bioinformatics 23(6):673-679

4. Ding J, Wang C, Xie Z, Li J, Yang Y, Mu Y, Tang X, Xu B, Zhou J, Huang Z (2015) Proterties of a newly identified esterase from Bacillus sp. K91 and its novel function in diisobutyl phthalate degradation. 
PLoS ONE 10(3):e0119216

5. Feng NX, Feng YX, Liang QF, Chen X, Xiang L, Zhao HM, Liu BL, Cao G, Li YW, Li H, Cai QY, Mo CH, Wong MH (2021) Complete biodegradation of di-n-butyl phthalate (DBP) by a novel Pseudomonas sp. YJB6. Sci Total Environ 761:143208

6. Frank JA, Reich Cl, Sharma S, Weisbaum JS, Wilson BA, Olsen GJ (2008) Critical evaluation of two primers commonly used for amplification of bacterial 16S rRNA genes. Appl Environ Microbiol 74(8):2461-2470

7. Jin D, Bai Z, Chang D, Hoefel D, Jin B, Wang P, Wei D, Zhuang G (2012) Biodegradation of di- $n$-butyl phthalate by an isolated Gordonia sp. strain QH-11: Genetic identification and degradation kinetics. J Hazard Mater 80:5

8. Jin D, Kong X, Cui B, Bai Z, Zhang H (2013) Biodegradation of di-n-butyl phthalate by a newly isolated halotolerant Sphingobium sp. Int J Mol Sci 14(12):24046-24054

9. Jin D, Kong X, Li Y, Bai Z, Zhang G, Zhuang X, Deng Y (2015) Biodegradation of di-n-butyl phthalate by Achromobacter sp. isolated from rural domestic wastewater. Int J Environ Res Public Health 12(10):13510-13522

10. Le TN, Thuy M, Nguyen HMN, Nguyen VK, Nguyen AV, Vu ND, Yen NTH, Hoang AQ, Minh TB, Kannan K, Tran TM (2021) Profiles of phthalic acid esters (PAEs) in bottled water, tap water, lake water, and wastewater samples collected from Hanoi. Vietnam Sci Total Environ 788:147831

11. Li J, Chen J, Zhao Q, Li X, Shu W (2006) Bioremediation of environmental endocrine disruptor di-nbutyl phthalate ester by Rhodococcus ruber. Chemosphere 65(9):1627-1633

12. Liu T, Li J, Qiu L, Zhang F, Linhardt RJ, Zhong W (2020) Combined genomic and transcriptomic analysis of the dibutyl phthalate metabolic pathway in Arthrobactersp. ZJUTW. Biotechnol Bioeng 117(12):3712-3726

13. Kanehisa M, Goto S, Kawashima S (2004) The KEGG resource for deciphering the genome. Nucleic Acids Res 32:D277-D280

14. Kumar S, Stecher G, Li M, Knyaz C, Tamura K (2018) MEGA X: molecular evolutionary genetics analysis across computing platforms. Mol Biol Evol 35(6):1547-1549

15. Lagesen K, Hallin P, Rodland EA, Staerfeldt HH, Rognes T, Ussery DW (2007) RNAmmer: consistent and rapid annotation of ribosomal RNA genes. Nucleic Acids Res 35(9):3100-3108

16. Lowe TM, Eddy SR (1997) tRNAscan-SE: a program for improved detection of transfer RNA genes in genomic sequence. Nucleic Acids Res 25(5):955-964

17. Romanenko LA, Tanaka N, Svetashev VI, Kurilenko VV, Mikhailov VV (2013) Luteimonas vadosa sp. nov., isolated from seashore sediment. 63:1261-1266

18. Sun R, Wang L, Jiao Y, Zhang Y, Zhang X, Wu P, Chen Z, Feng C, Li Y (2019) Metabolic process of di-nbutyl phthalate (DBP) by Enterobacter sp. DNB-S2, isolated from Mollisol region in China. Environ Pollut 255:113344 
19. Sun D, Li H, Wang E, He W, Hao W, Yan C, Li Y, Mei X, Zhang Y, Sun Z, Jia Z, Zhou H, Fan T, Zhang X, Liu Q, Wang F, Zhang C, Shen J, Wang Q, Zhang F (2020) An overview of the use of plastic-film mulching in China to increase crop yield and water-use efficiency. Natl Sci Rev 7(10):1523-1526

20. Surhio MA, Talpur FN, Nizamani SM, Talpur MK, Afridi HI, Khaskheli AA, Bhurgri S, Surhio JA (2017) Leaching of phthalate esters from different drinking stuffs and their subsequent biodegradation. Environ Sci Pollut Res Int 24(22):18663-18671

21. Tang S, Yin H, Yu X, Chen S, Lu G, Dang Z (2021) Transcriptome profiling of Pseudomonas aeruginosa $\mathrm{YH}$ reveals mechanisms of 2, 2', 4, 4'-tetrabrominated diphenyl ether tolerance and biotransformation. J Hazard Mater 40(3):124038

22. Tatusov RL, Fedorova ND, Jackson JD (2003) The COG database: an updated version includes eukaryotes. BMC Bioinformatics 4:41

23. Vikelsoe J, Thomsen M, Carlsen L (2002) Phthalates and nonylphenols on profiles of differently dressed soils. Sci Tital Environ 296:105-116

24. Wang L, Sun X, Chang Q, Tao Y, Wang L, Dong J, Lin Y, Zhang Y (2016) Effect of di- $n$-butyl phthalate (DBP) on the fruit quality of cucumber and the health risk. Environ Sci Pollut Res Int 23(23):2429824304

25. Wang Q, Wu X, Jiang L, Fang C, Wang H, Chen L (2020) Effective degradation of Di- $n$-butyl phthalate by reusable, magnetic FeO nanoparticle-immobilized Pseudomonas sp. W1 and its application in simulation. Chemosphere 250:126339

26. Wang X, Wu H, Wang X, Wang H, Zhao K, Ma B, Lu Z (2021) Network-directed isolation of the cooperator Pseudomonas aeruginosa ZM03 enhanced the dibutyl phthalate degradation capacity of Arthrobacter nicotianae ZM05 under pH stress. J Hazard Mater 410:124667

27. Wu J, Liao X, Yu F, Wei Z, Yang L (2013) Cloning of a dibutyl phthalate hydrolase gene from Acinetobactersp. strain M673 and functional analysis of its expression product in Escherichia coli. Appl Microbiol Biotechnol 97(6):2483-2491

28. Wu X, Wang Y, Liang R, Dai Q, Jin D, Chao W (2011) Biodegradation of an endocrine-disrupting chemical di-n-butyl phthalate by newly isolated Agrobacterium sp. and the biochemical pathway. Process Biochem 46:1090-1094

29. Xu XR, Li HB, Gu JD (2015) Biodegradation of an endocrine-disrupting chemical di- $n$-butyl phthalate ester by Pseudomonas fluorescens B-1. Biodegradation 26:171-182

30. Xu W, Wan Q, Wang W, Wang Y, Feng F, Cheng J, Yuan J, Yu X (2020) Bacillus subtilis biodegradation of dibutyl phthalate by a novel endophytic strain HB-T2 under and conditions. Environ Technol1-10

31. Zhang Q, Ma Z, Cai Y, Li R, Ying G (2021) Agricultural plastic pollution in China: generation of plastic debris and emission of phthalic acid esters from agricultural films. Environ Sci Technol. doi:10.1021/acs.est.1c04369

32. Zhang XY, Fan X, Qiu YJ, Li CY, Xing S, Zheng YT, Xu JH (2014) Newly identified thermostable esterase from Sulfobacillus acidophilus: properties and performance in phthalate ester degradation. Appl Environ Microbiol 80(22):14 
33. Zhao Z, Liu C, Xu Q, Ahmad S, Zhang H, Pang Y, Aikemu A, Liu Y, Yan H (2021) Characterization and genomic analysis of an efficient dibutyl phthalate degrading bacterium Microbacterium sp. USTB-Y. World J Microbiol Biotechnol 37(12):212

\section{Figures}

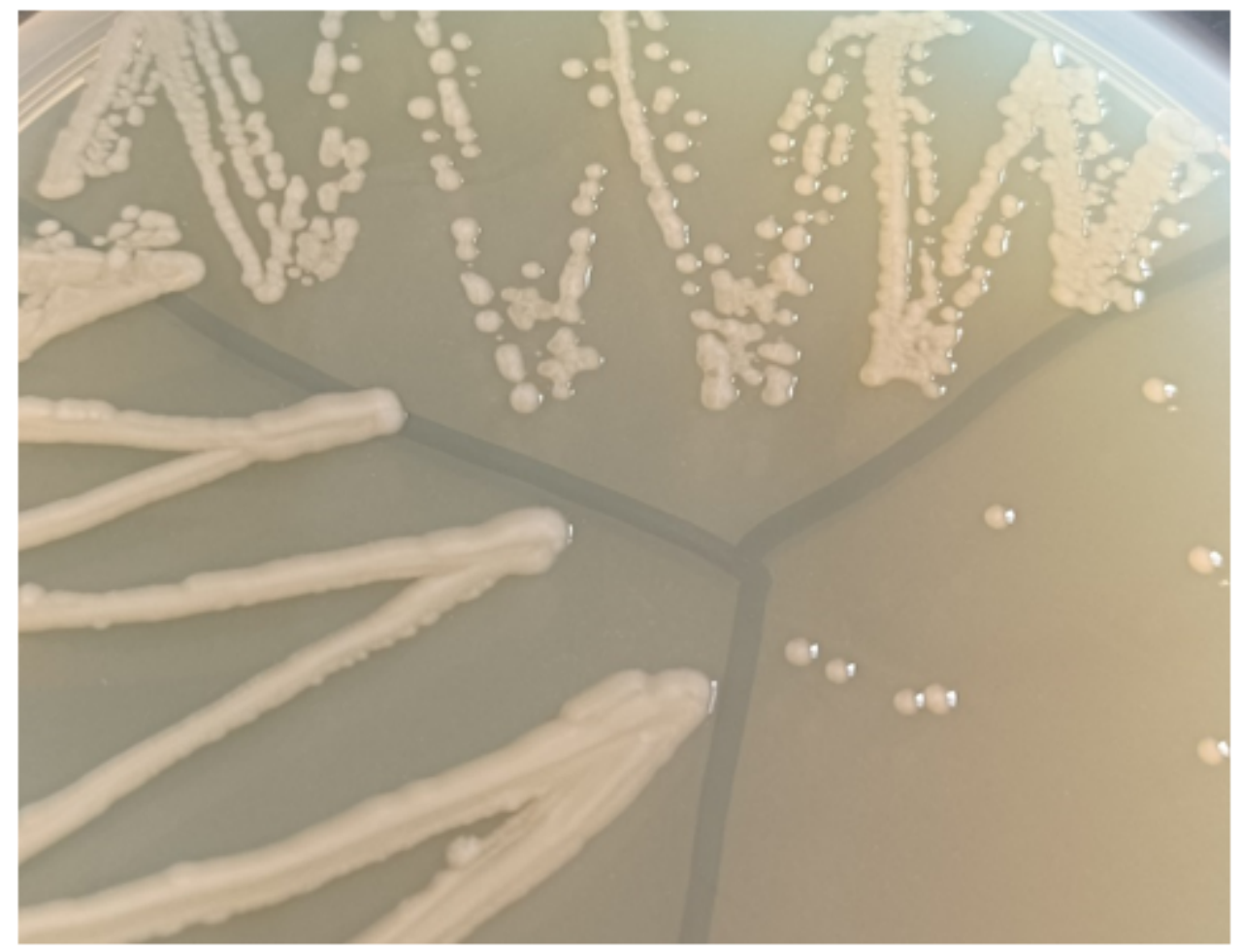

\section{Figure 1}

The morphologic feature of strain $\mathrm{J} 2$ 


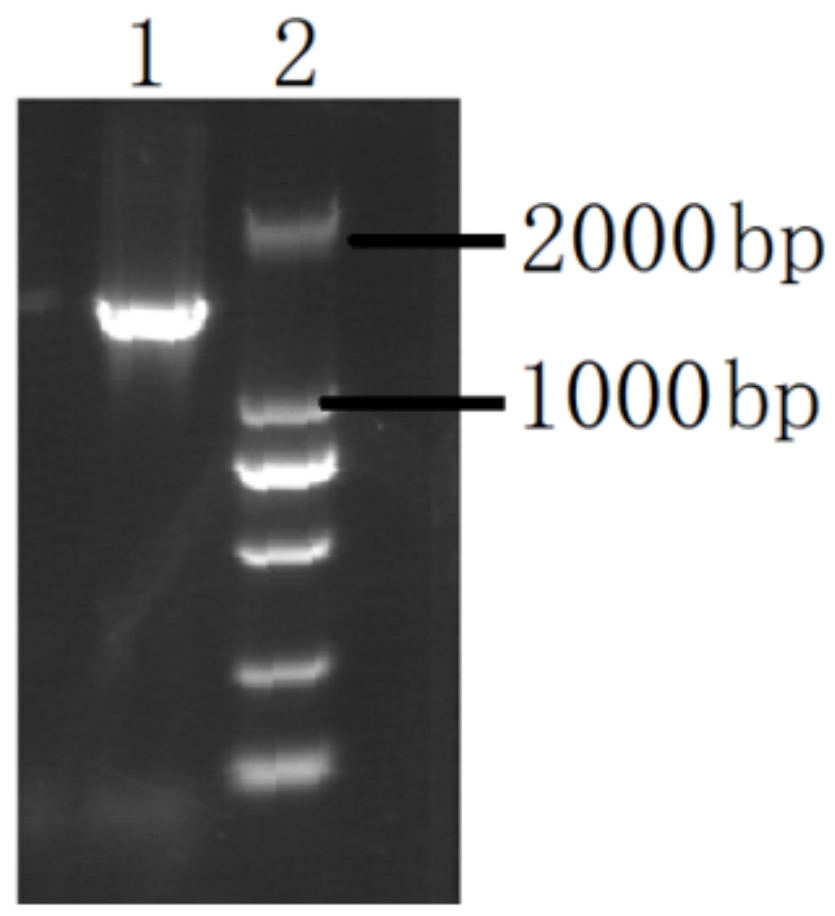

Figure 2

Electrophoretic profiles of 16S rRNA gene, Lane 1 was $16 \mathrm{~S}$ rRNA gene of stain J2, lane 2 was DNA Marker

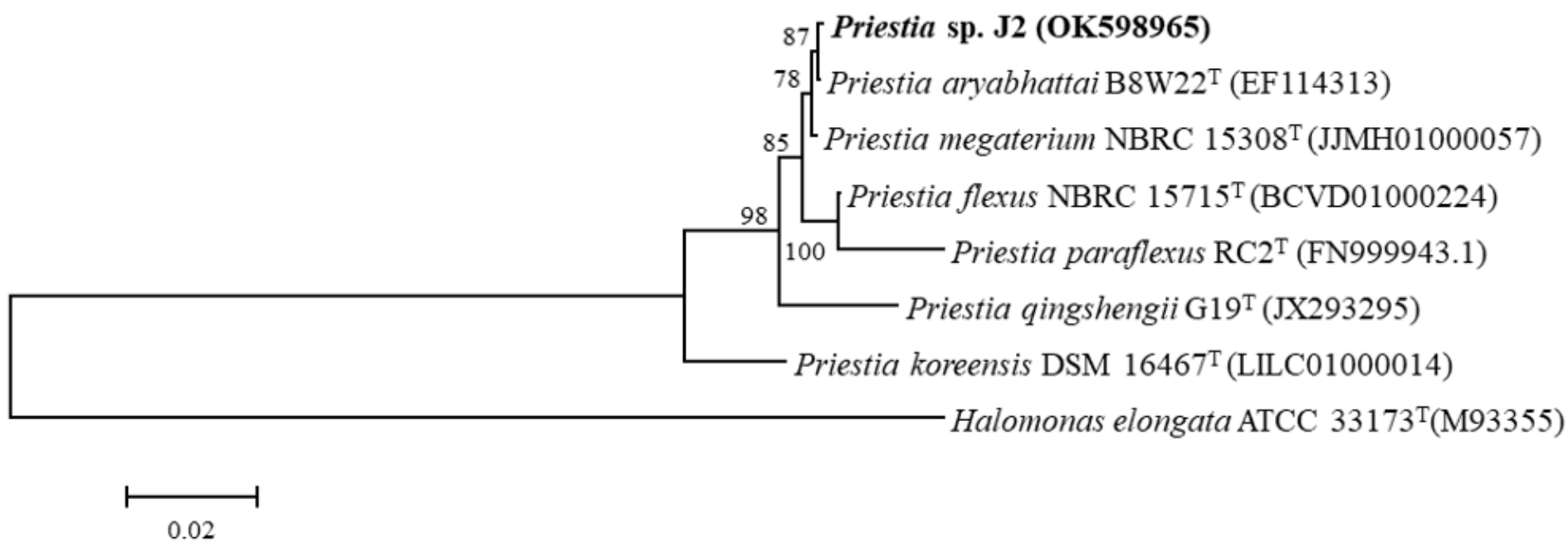

Figure 3

Phylogenetic tree based on 16S rRNA gene sequence. Bootstrap values based on 1000 replication are shown at branch node. Halomonas elongata ATCC $33173^{\top}$ was used as an outgroup. 

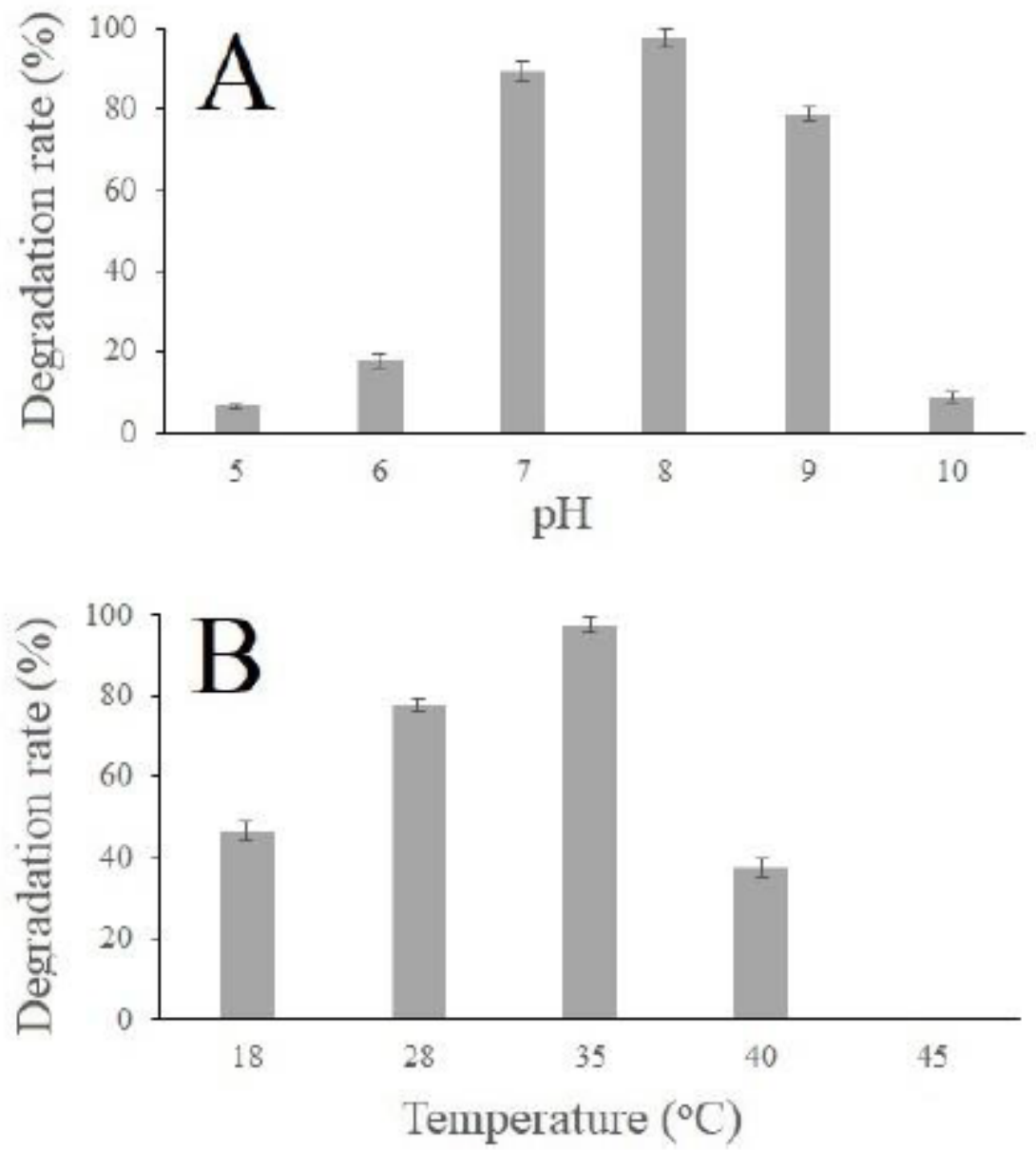

Figure 4

Effect of $\mathrm{pH}$ and temperature on biodegradation of DBP by Priestia sp. J2. 

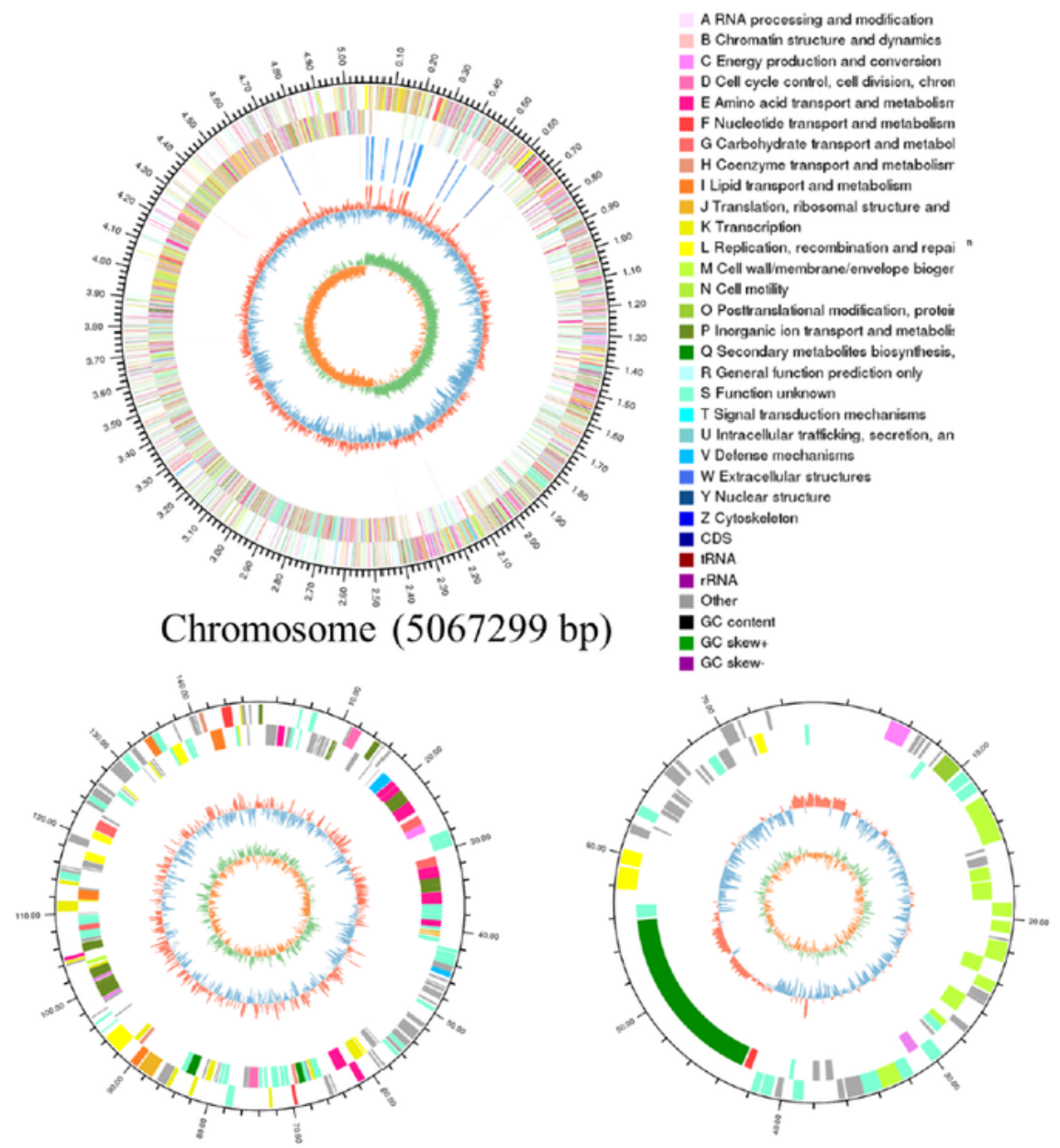

Plasmid A (147924 bp)

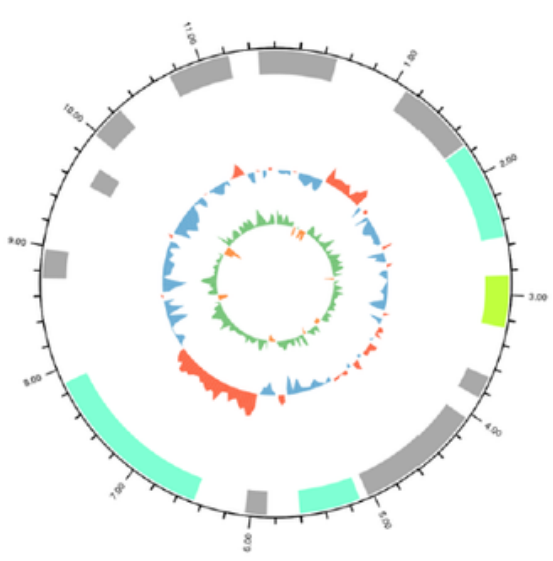

Plasmid C (11604 bp)
Plasmid B (75940 bp)

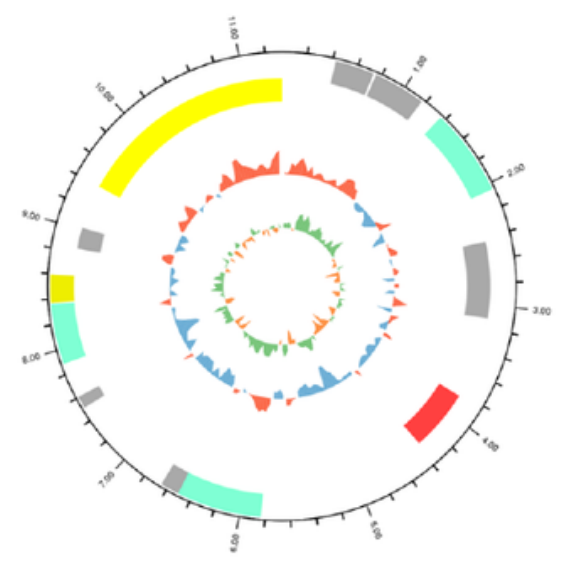

Plasmid D (11333 bp)

\section{Figure 5}

Circular map of the complete genome of Priestia sp. J2. 


\begin{tabular}{|c|c|c|}
\hline Est-J2-1 & $\cdots \cdots$ & 0 \\
\hline DphB & $\ldots m \cdots \cdots \cdots \cdots \cdots \cdots \cdots \cdots \cdots \cdots \cdots \cdots$ & $\theta$ \\
\hline DBP_hydrolase & MNSAIKGTNVTALPQKIQTILDKGQGPAARALDKFPKIVQ & 40 \\
\hline Ests̄1 & 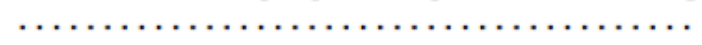 & $\theta$ \\
\hline Est-J2-1 & $\ldots \ldots \ldots$ MPLDPHIQIFLNQYNEMPRP . . . SLEDVTP & 27 \\
\hline DphB & ... MNDGATRYTRPDVAAFLAFLNAQEGP . . . KMEDMPP & 33 \\
\hline DBP_hydrolase & ESLAKVLGYPYQYPDLDAFTKCLMAVQIKQGRIGFIGEDP & 80 \\
\hline Est $\bar{s} 1$ & DPRVEQFLAQMPPLNRE....GLSLAEA & 27 \\
\hline Est-J2-1 & LQLREMEKMS. . LTPSKE.AVKKVYNEEIQLNERTLTIRV & 64 \\
\hline DphB & DGAREMFRVMGQLADVPRGDIAKVEDRTIPGPAGDIAIRI & 73 \\
\hline DBP_hydrolase & IESRRQFDAQMLAILNKATQIESVEDIRLPLQSGTVFARH & 120 \\
\hline Ests̄1 & RQQFKQGALL . . LDQMVPPPPVDTEDGTVVTTHGPVRIRR & 65 \\
\hline Est-J2-1 & GWVLGSLDTHDSICRSYANET & 103 \\
\hline DphB & GGWVIGDLDTHDPYCAEAARQL & 113 \\
\hline DBP_hydrolase & GGGFVVGGLDTHDEVCRLIAKYA & 159 \\
\hline Ests1 & YIPDRLR. FSHPLVFYHGGGFVFGDIDTHHGLVARLCQTV & 104 \\
\hline Est-J2-1 & EVISAHAFQLNI & 143 \\
\hline DphB & TRWVADN.....I & 148 \\
\hline DBP_hydrolase & LLIKSCEDALAWVYQNRRQLKI & 199 \\
\hline Est $\bar{S} 1$ & IPVAECIDVARLAAHEAPGWGL & 144 \\
\hline Est-J2-1 & $D S A G G N L A A V A S I L A K Q R Q G P S$. IVHQLLIY & 182 \\
\hline DphB & ACTGLVLSESAG SN LTIATALTLRDRPASKPVLAMHPIY & 188 \\
\hline DBP_hydrolase & YKNRIAVA GDSAG SN ISTVVAQHTAGKSYAP. . QAQLLIY & 237 \\
\hline EstS1 & SAG GNLAAVVSQRAKDESLP. . IAAQLLFY & 181 \\
\hline Est-J2-1 & GYLLSKDLMDWFRLQY'YNNKEE & 222 \\
\hline DphB & PAVTTHNDWQS.YRDFGEGHLLTTGSMTWFGNHYAADPAD & 227 \\
\hline DBP_hydrolase & PVVDFKSRHPS. FYAYGEGLVLTSKDVDYVTQYYATQHNI & 276 \\
\hline EstS1 & PALDMVHETPS. KRDFARGYLLEADAMQWFGEQYLRTPDD & 220 \\
\hline Est-J2-1 & EQHPYNAPVLLEDLSSL & 262 \\
\hline DphB & ....YRAS & 263 \\
\hline DBP_hydrolase & ALDNPLISPTYGNLRKL & 316 \\
\hline EstS1 & VSHPWASPALSPDLTGLPPALVITAE & 260 \\
\hline Est-J2-1 & LKNHGVPVTYENYETMIHGFLGFHEFVPLAQQAINKSAAQ & 302 \\
\hline DphB & LVEAGVPTTYREAKGNIHGYINLSQGIPSAKDDIRGALTL & 303 \\
\hline DBP_hydrolase & LRQSGVKVQYVDYPDQTHGFINLTPISSKAKRNTIEIAKN & 356 \\
\hline Ests1 & LRAAGVPTEQIRFDGMIHGFMTMPIF. PQMEAAIEAVARF & 299 \\
\hline Est-J2-1 & LRQVFDSI. . & 310 \\
\hline DphB & LKAIVAEANGA & 314 \\
\hline DBP_hydrolase & FRKFWDKHS. . & 365 \\
\hline Ests̄i & LERID. . . . . & 304 \\
\hline
\end{tabular}

\section{Figure 6}

Multiple-sequence alignment of esterases from Priestia sp. J2 (Est-J2-1, in this study), wastewater treatment plant (DphB) (KC438416), Acinetobacterap. M673 (DBP hydrolase) (AFK31309), and Sulfobacillus acidophilus (EstS1) (AEW03609). The catalytic triad Ser154, Asp250, and His280 in the EstJ2-1 from Priestia sp. J2, is indicated by arrows. The consensus sequence Gly-X-Ser-X-Gly around the active-site Ser154 is boxed in the black frame. 